\title{
Review of Ames Assay Studies of the Urine of Clinical Pathology and Forensic Laboratory Personnel and Other Occupations, such as Oncology Hospitals and Nursing Personnel
}

\author{
Majid Rezaei Basiri1,6, Mahmoud Ghazi-khansari², Hasan Rezazadeh1, \\ Mohammad Ali Eghbal ${ }^{1,5^{*}}$, Iraj Aswadi-kermani ${ }^{4}$, H. Hamzeiy ${ }^{1}$, \\ Hossein Babaei ${ }^{1}$, Ali Reza Mohajjel Naebi ${ }^{1}$ and Alireza Partoazar ${ }^{2,3}$ \\ ${ }^{1}$ Department of Pharmacology and Toxicology of Tabriz Pharmacy School, \\ Tabriz University of Medical Sciences, Tabriz, \\ ${ }^{2}$ Department of Pharmacology in School of Medicine in \\ Tehran Medical Sciences University, Tehran, \\ ${ }^{3}$ Laboratories of Forensic Organization of Tehran, Tehran, \\ 4Shahid Ghazi Oncology Research Centre in Tabriz Medical Sciences University, Tabriz, \\ ${ }^{5}$ Drug Applied Research Centre of Tabriz Medical Sciences University, Tabriz, \\ ${ }^{6}$ Students Researches Committee of Tabriz University of Medical Sciences, Tabriz,
}

Iran

\section{Introduction}

This chapter we refer to mutagenicity activity in the urine samples of persons who are exposed to carcinogenic materials in their occupations, and so some studies evaluated mutagenicity determination in individuals who worked with and are exposed to active potential mutagenic materials. There are some mutagenic compounds present in workplaces such as among nursing personnel in oncology hospitals, farmers' fields, clinical pathology laboratories, clinical forensic laboratories and pharmacology investigation laboratories etc. Also, clinical forensic laboratory personnel use some dangerous solvents such as chloroform which is mixed with other solvents in solutions of preparations of tank thin layer chromatography. They are also exposed to some mutagenic compounds such as formaldehyde, benzene and some solvents and colour regents. We refer to some of the below mentioned compounds, such as benzene, formaldehyde, paraffin, colour regents, organochlorin, smear fixators and so on. The colour regent might be contained in heavy metal carcinogenic substances which were used for smear colouring in clinical pathology laboratories by technicians and clinical forensic laboratories. According to review of some studies, after the filling out of questionnaire forms by these individuals, urine samples were

${ }^{*}$ Corresponding Author 
collected from candidates in all occupations at the end of the week and they were then held in a refrigerator for the urine extraction process. Special instruments - such as vacuum - and special materials such as MilliQ water and some solvents such as methanol and acetonitrile were used for urine solid phase extraction. Some relationship studies showed that urine extracts were prepared by resins of $\mathrm{C} 18$ and amberlite XAD-2 because they are particularly absorbent of the carcinogenic compounds of urine; the importance of the above mentioned resins and the sterilisation of urine extracts will be described in this chapter as well. The personnel who work for a long time in these fields are exposed to these potentially carcinogenic materials. According to the review studies, we will show the mutagenic activity evaluation of the urine of some professional personnel by Ames monitoring. After the preparation of the sterile urine extracts of these personnel, they were exposed to salmonella strains of bacteria for the determination of mutagenic activity. The function of salmonella typhimorium strains such as: TA98,TA100, and the overnight culture of these bacteria show the importance of suspension preparation in the Ames test ratio and all kinds of bacterial environment cultures and the holding of the above mentioned bacteria will be considered in this chapter too. All methods of Ames assay application in these work places will be explained in detail in this chapter. And finally, a risk-benefit assessment and the conditions of healthy work places and individuals' protection will be described as well at the end of this chapter.

\section{Mutagenic or carcinogenic material}

Some compounds are present in the occupations of clinical pathology and forensic laboratory personnel and other occupations, such as oncology hospitals. Others in this review are: hamatoxilene, eosin and some solvents and colour reagent. Benzene, formaldehyde, paraffin, colour reagents, organochlorin, smear fixators, antineoplastic drugs etc. So the personal of these places might absorb these materials in their work environment through the lungs, the skin, orally etc. These compounds are metabolised in their liver by the P450 enzyme to activate potential mutagenic compounds. Figure.1 shows some these compounds. $[5,6,7,8,9,10,12,13,14,15,17,18,19,20,21]$

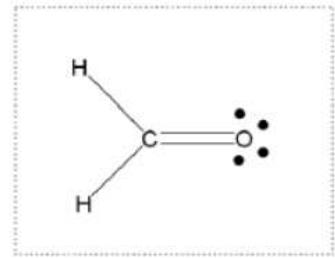

Formaldehyde

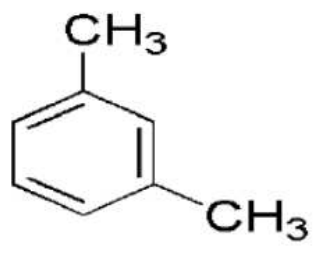

M-Xylene

Fig. 1. Mutagenic or Carcinogenic material in laboratory, oxide metabolites of these compounds cause genotoxic effects.

\section{Samples and Ames test history}

For the mutagenicity activity evaluation of biological fluids in different job environments in previous decades, numerous studies of the founder of mutagenicity have a review up 
technique called Ames assay. The first experiments by professor Ames and his co-workers were conducted in the 1960s and 1970s and they were accepted by international agencies, including the American FDA. The test has its own specific conditions because it shows that mutagenicity activities with cost less and the samples of tested results would be expressed in a few days. As well as this, it can simultaneously test up some carcinogenic material over the same time in less than three days. It is held that it also tested for ease of mutagenicity activities which are available for review, of which there may be more in the future. However, in many work environments there are promutagenic and carcinogenic compounds that are present to which workers are exposed. The review of studies of more jobs and environments globally show that using this test for biological fluids - including the urine of personnel - proves potential mutagenic activities. It is also held that the assessment of them in all jobs as well as review by the study process including the preparation of urine samples, extraction of urine mutagenic compounds and the Ames test performed on the samples and biological extracted compounds have similarities processes. $[1,2,3,6,12,13,17]$

\section{Sampling of volunteers and urine extraction}

All of the urine samples were collected at the end of the week from the Iranian forensic organisation's laboratories and other relationship laboratories personnel and stored in a refrigerator, although some appropriate methods are accessible for the urine extracts' preparation, but in this review we almost see solid phase extraction methods. Extraction columns were filled with $1 \mathrm{~g}$ from one kind of C18 or XAD-2 resins between two layers of cotton, depending on studies' strategies. First, the resins were activated by Milli-Q water and methanol then the volunteer's clear urine was passed through a column by vacuum and the mutagenic substances were concentrated with $\mathrm{V} / \mathrm{V}$ of methanol/Acetonitrile in tubes. $[3,4,6,12,17]$

\section{Ames assay}

In these studies, mutagenicity was followed by the plates' incorporated procedures, as described by Mortelmans and Zeiger (2000), in overnight cultures of TA98 and TA100 salmonella typhymorium tester strains with and without the S9 mix fraction in the forensic organisation's personnel and just TA100 in the clinical laboratory technicians in Iranian laboratories. For this strain, the spontaneous background number of the revertant was approximately 20-50 for TA98 and 75-200 for TA100 salmonella typhymorium tester strains. In this study, Sodium azide was used as a positive control without using the S-9 mix buffer and the 2-amino anthracene as a positive control with the S-9 mix buffer. DMSO and distilled water were considered as negative controls and were used in this study. $[1,2,3,6,12,13,17]$

\section{Ames assay protocol}

The first dose/response was determined for all urine extract samples. In our studies, the appropriate dose of urine extracts was $1 / 100$ for exposed bacterial strains and $0.05 \mathrm{ml}$ of overnight bacterial culture (TA98 or TA100) was added in $2 \mathrm{ml}$ of melting top agar containing trace amounts of biotin and histidine then, and $0.05 \mathrm{ml} 1 / 100$ of diluted urine extract with DMSO solvent was added in the melting top agar tube as well; after shaking the tube's contents were transferred in Glucose minimum agar plates which were incubated at $37 \mathrm{C}$ for 48 hours. The above mentioned protocols were repeated with the addition of $0.5 \mathrm{ml}$ 
of the S-9mix buffer with the contents of the rat liver p450 enzyme. After the incubation of all plates with and without S-9mix buffer, the colony counts of all the plates were reported for data collection. $[1,2,3,4,6,12,13,17]$

\section{Ames assay on urine samples of hospitals nursings}

Most of the anti-neoplastic drugs are cytotoxic as well as nephrotoxic and cause DNA damage. For example, some of them are: doxorubicin, bleomycin, vinblastine, dacarbazine, methotrexate, fluorouracil , prednisone, epirubicin, irinotecan, leucoverin, prednisone, 6-mercaptopurine, procarbazine, lomustine, cisplatin (platinum), etoposide, 6-thioguanine, dexamethasone. According to figure.2, these drugs (such as cycloposphamide, mechlortamine, melphalan, chlorambucil) are nitrogen mustard group and so they have genotoxic effects because they will link to DNA, and they have carcinogenic effects on individuals who are exposed to them in their occupations. They involve a rapid proliferation of normal tissues (bone marrow, hair follicles and the intestinal epithelium). Therefore, most hospital nursing personnel are chronically exposed to anti-neoplastic drugs, especially during the course of giving therapeutic doses to cancer patients. Some studies have shown mutagenic activity in the urine of these nursing staff through an Ames assay. $[3,4,6,7,8,9,11,12,13,17]$

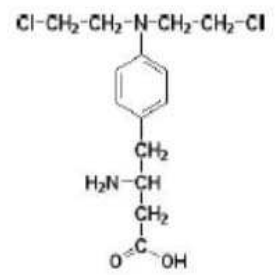

Melphalan

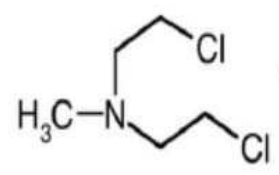

Mechlorethamine

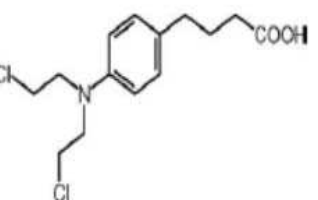

Chlorambucil

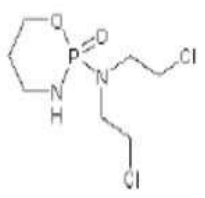

Cyclophosphamide

Fig. 2. Some antineoplastic drugs with nitrogen mustard groups.

\section{Studies' results}

The data was collected from all the occupational personnel and their negative group control urine extracts were exposed to salmonella bacteria tester strains, such as TA98 and TA100 in these review studies; then, according to the below mentioned results and data from the Iranian clinical pathology and medicinal forensic laboratories, they show the colony counts of all the tester strains of salmonella typhymorium bacteria (such as TA 98 and TA100) as being more than 400 for the positive samples of personnel. On the other hand, the colony count of these individuals' urine samples in the bacterial culture shows that these personnel excrete mutagenic compounds in their urine. Each ratio is determined from individuals' urine samples colony counts per negative group of control 
persons' urine sample colony counts, so the ratio of all the samples was more than 2 and significant for the description of mutagenic compounds in all occupations. According to figure.3, in these studies we used a $0.05 \mathrm{ml}$ DMSO solvent and diluted water for negative control plates with and without using the S-9mix buffer, and we also used sodium azide for positive control plates without using the S-9mix buffer and 2-amino anthracene for positive control plates with the S-9mix buffer.

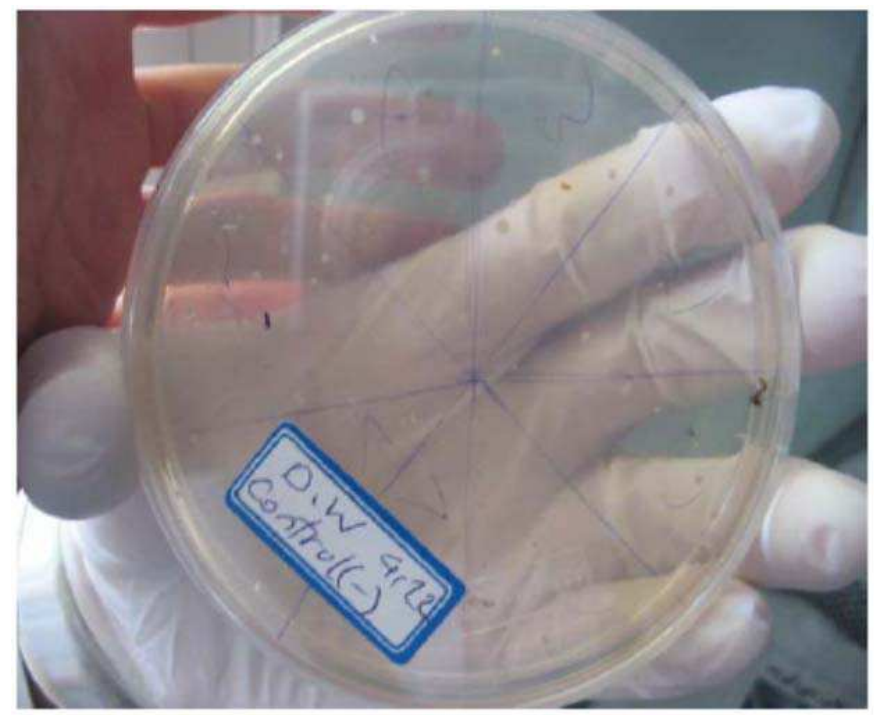

Fig. 3a. Diluted water (D.W) for the negative control colony count plate without using the S-9 mix buffer. Rezai-basiri et al., 2008.
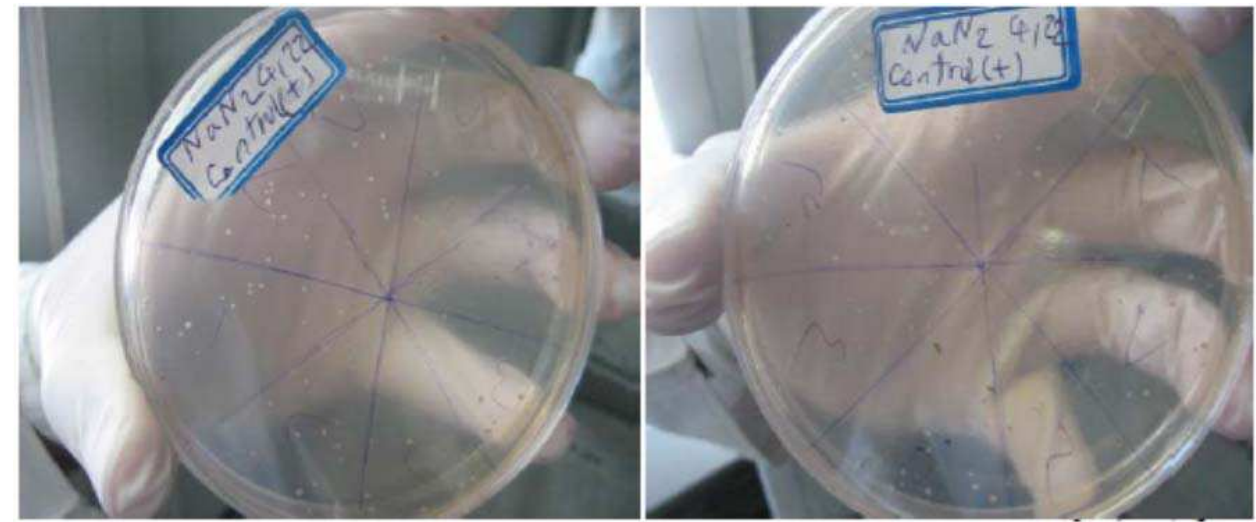

Fig. 3b. Sodium azide ( $5 \mu \mathrm{g} /$ plate) for the positive control colony count plate (and TA100 Salmonella typhymorium tester strain) without using the S-9 mix buffer. Rezai-basiri et al., 2008. 


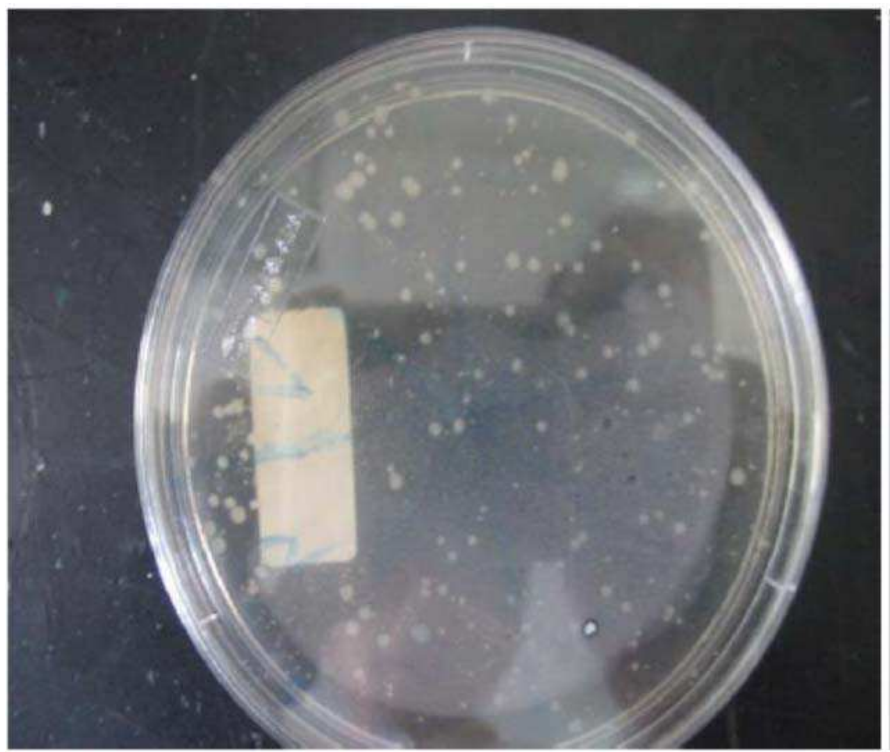

Fig. 3c. DMSO for the positive control colony count plate (and TA100 Salmonella typhymorium tester strain) with using the S-9 mix buffer. Rezai-basiri et al., 2008.

\section{Statistical analysis methods}

In the Ames assay on the Iranian forensic organisation's laboratory personnel's urines with two bacterial tester strains of TA98, TA100 for colony counts in exposure to urine extract samples, and positive or negative samples the Anova two-way statistical method was used.

\section{Evaluation of mutagenic compounds the in urine of medicinal forensic laboratory personnel}

\begin{tabular}{lcccc}
\hline Control group & \multicolumn{2}{c}{ Colony count TA100 } & \multicolumn{2}{c}{ Colony countTA98 } \\
\hline Male & without-S-9mix & with+S-9mix & without-S-9mix & with+S-9mix \\
Male & 86 & 65 & 26 & 25 \\
Male & 106 & 72 & 23 & 27 \\
Male & 100 & 77 & 27 & 21 \\
Male & 85 & 75 & 19 & 24 \\
Male & 88 & 68 & 22 & 25 \\
Male & 98 & 65 & 21 & 14 \\
Female & 95 & 85 & 23 & 29 \\
Female & 91 & 85 & 20 & 28 \\
Female & 102 & 86 & 24 & 24 \\
\hline Average & 98 & 76 & 18 & 24.7 \\
\hline
\end{tabular}

Partoazr, et al., 2009.

Table 1. Results of the control group of the mutagenicity assay in the urine of medicinal forensic laboratory personnel with the use of TA98 and TA100 bacteria strains both with and without the S-9mix. 
Review of Ames Assay Studies of the Urine of Clinical Pathology and Forensic

\begin{tabular}{|c|c|c|c|c|}
\hline Samples & \multicolumn{2}{|c|}{ Colony count TA100 } & \multicolumn{2}{|c|}{ Ratio of TA100 } \\
\hline & with+S-9mix & without-S-9mix & without-S-9mix & with+S-9mix \\
\hline $1^{*}$ & 95 & 95 & 1 & 1.26 \\
\hline $2^{*}$ & 95 & 78 & 1 & 1.04 \\
\hline $3^{* *}$ & 85 & 74 & 0.89 & 0.98 \\
\hline
\end{tabular}

*=The samples belonged to the pathology personnel of the medicinal forensic organisation.

**=The samples belonged to the anatomy personnel of the medicinal forensic organisation. Partoazr, et al., 2009.

Table 2. Positive and doubtful cases. The results of the mutagenicity assay in the urine of medicinal forensic laboratory personnel with the use of TA100 salmonella typhymorium bacteria strains both with and without the S-9mix (cell of rat liver).

\begin{tabular}{lcccc}
\hline Samples & \multicolumn{2}{c}{ Colony count TA98 } & \multicolumn{2}{c}{ Ratio of TA98 } \\
\hline $1^{* *}$ & with+S-9mix & without-S-9mix & without-S-9mix & with+S-9mix \\
$2^{*}$ & 550 & 55 & 20 & 2.2 \\
$3^{*}$ & 340 & 30 & 15 & 1.2 \\
\hline
\end{tabular}

$* *=$ Positive cases in the personnel of the medicinal forensic organisation.

*=Doubtful cases in the personnel of the medicinal forensic organisation. Partoazr, et al., 2009.

Table 3. Positive and doubtful cases. The results of the mutagenicity assay in the urine of medicinal forensic laboratory personnel with the use of TA98 salmonella typhymorium bacteria strains both with and without the S-9mix (cell of rat liver).

\section{Evaluation of mutagenic compound in urine of clinical pathology laboratory technicians}

At least four clinical pathology laboratories witnessed the evaluation of the mutagenicity of the urine of technicians by the Ames assay. That the ratio would be more than two was significant for the potential of the mutagenic activity of the urine of technician.

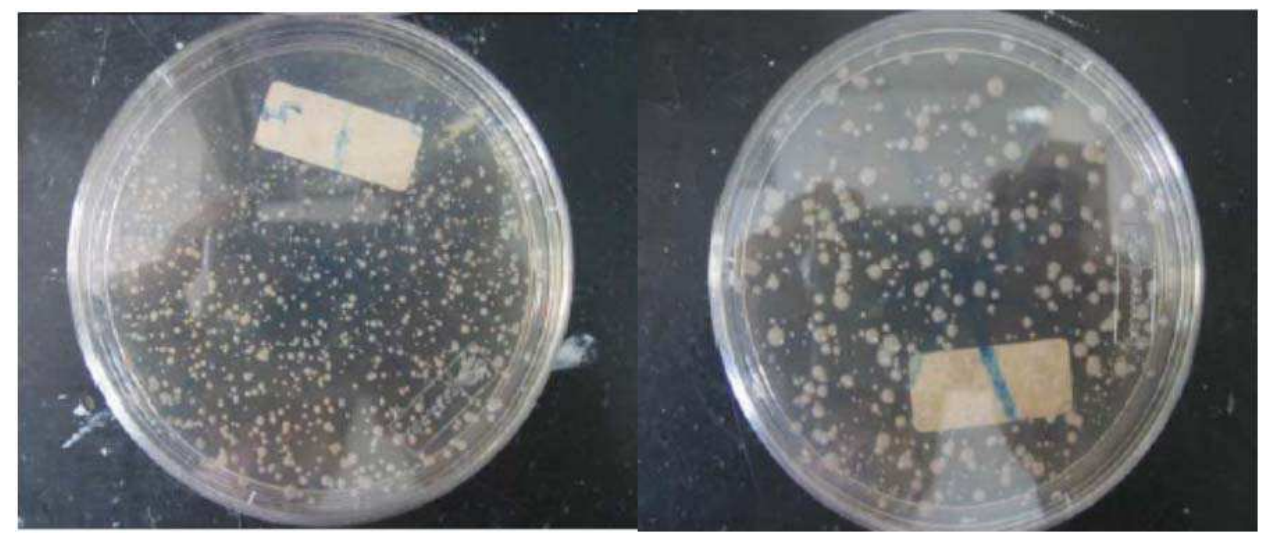

Fig. 4. The plates of positive cases of the TA100 salmonella tester strain cultures at 37C for 48hours for the Ames assay on the urine extracts of the clinical pathology laboratory technicians. Rezai-basiri et al., 2008. 
The number of personnel who had greater than two ratios was five people in this study. According to the below mentioned, we see some significant results showing mutagenic excretions in the urine of clinical pathology laboratory technicians:

The ratios without the S-9mix for two of the technicians were 2.01 and 2.0, and the ratio with the S-9mix for these individuals was 2.05 and 2.01. $[3,6,12,13,17]$

\section{Conclusion and recommendation}

In this review study, we observed mutagenic activity in the urine extracts of some of the technicians of clinical pathology laboratories and the forensic organisation laboratories. According to these studies, in order to reduce mutagenicity in technicians it was suggested to all of them to use masks, gloves and work under laminar flu and avoid drinking in the laboratories. Considering the contamination of all personnel with mutagenic substances such as colour reagents contained in carcinogenic heavy metals, formaldehyde, benzene, hamatoxilen-Eosin and so on in these laboratories, the observation of the principles of health conditions in clinical pathology laboratories and forensic organisation laboratories is recommended. According to this review study, it is held that the long duration of working and exposure to mutagenic and carcinogenic substances in high risk conditions leads to the excreting of mutagenic compounds in the urine of these individuals and so they should decrease their time spent working over the week. The some studies showed which personnel has used antioxidant compounds, such as thiol group drugs; they had decreased the mutagenic activity in their urine. Also these results were shown to smokers who have used thiol group drugs such as acetyl cystein, had low mutagenic activity in urine samoles. As such, it considers the consumption of vitamins with antioxidant effects which are useful to individuals who are exposed to mutagenic compounds in their occupations. $[3,6,12,13,16]$.

\section{Acknowledgments}

We are grateful to the below mentioned departments and the research centres of universities and organisation laboratories as well as to the volunteer personnel for their participation in these studies and their professors for the writing of this article:

Department of Pharmacology in the School of Medicine of Tehran/Iran Medical Sciences University.

Department of Pharmacology and Toxicology in the School of Medicine of Tabriz/Iran Medical Sciences University.

Laboratories of Forensic Organization of Tehran/Iran.

Shahid Ghazi Oncology Research Centre Department in Tabriz/Iran Medical Sciences University.

Drug Applied Research Centre of Tabriz/Iran.

Students Researches Committee of Tabriz/Iran Medical Sciences University.

\section{References}

[1] Mortelmans K, Zeiger E, the Ames Salmonella/Microsome Mutagenicity Assay; Mutat Research, 2000, 29-60. 
[2] Zeiger E, Genotoxicity Database, Hand book of carcinogenic potency and genotoxicity database, CRS Press, Boca Raton, FL, 1997, 687-729.

[3] Andre V, Deslandes D, Henry-Amar M, Gauduchon P, Biomonitoring of urine mutagenicity with the Ames test: improvement of the extraction/concentration method, Mutat Res, 2002; 520(1-2): 199-205.

[4] Hyde PM, Evaluation of drug extraction procedures from urine, J Anal Toxicol, 1985, 9(6): 269-72.

[5] Aeschbacher HU, Finot PA, Wolleb U, Interaction of histidine- containing test substances and extraction methods with the Ames mutagenicity test, Mutation Res, 1983; 113(2): 103-16.

[6] Andre V, Lebailly P, Pottier D, Deslandes E, De Meo M, Henry-Amar M, Gauduchon P, Urine mutagenicity of farmers occupationally exposed during a 1-day use of chlorothalonil and insecticides, Int Arch Occup Environ Health, 2003, 76(1): 55-62.

[7] Ahlborg G Jr, Bergstrom B, Hogstedt C, Einisto P, Sorsa M, Urinary screening for potentially genotoxic exposures in a chemical industry, Br J Ind Med, 1985, 42(10): 691-9.

[8] Harrison BR, Developing guidelines for working with antineoplastic drugs, Am J Hosp Pharm, 1981, 38(11): 1686-93.

[9] Zimmerman PF, Larsen RK, Barkley EW, Gallelli JF, Recommendations for the safe handling of injectable antineoplastic drug products, Am J Hosp Pharm, 1981, 38(11): 1693-5.

[10] Anderson RW, Puckett WH Jr, Dana WJ, Nguyen TV, Theiss JC, Matney, TS, Risk of handling injectable antineoplastic agents, Am J Hosp Pharm,1982;39(11):1881-7.

[11] Rezaei-Basiri M, Ghazi-khansari M, Faghih A, Sadeghi M, Lotfalizadeh N, Eghbal M, Mohajell-Nayebi A, Rezazadeh H, Arshad Zadeh M, Screening of Morphine \& Codeine in Urine of Opioid Abusers by Rapid and TLC Analysis, Eur J Gen Med, 2010, 7(2): 192-196.

[12] Rezaei-Basiri M, Samini M, Ghazi- khansari M, Rezayat M, Sahebgharani M and Partoazar A, Monitoring Ames Assay on Urine of Clinical Pathology Laboratories Technicians, Journal of Pharmacology and Toxicology, 2008, 3 (3): 230-235.

[13] Partoazar A, Ghazi -Khansari M, Abedi MH, Kaviani M, Norashrafeddin SM, RezaeiBasiri M,Talebi M, Determining urine sample mutagenicity ratio using Ames test: Tehran forensic medicine laboratory personnel, Tehran University Medical Journal, June 2009, 67(3): 184-189.

[14] Shelef LA and Chin B, Effect of Phenolic Antioxidants on the Mutagenicity of Aflatoxin B1, Applied and Environmental Microbiology, Dec. 1980: 1039-1043.

[15] Cerná M, Pastorková A, Bacterial urinary mutagenicity test for monitoring of exposure to genotoxic compounds: a review, Sep. 2002, 10(3): 124-9.

[16] De Flora S, Camoirano A, Bagnasco M, Bennicelli C, van Zandwijk N, Wigbout G, Qian GS, Zhu YR, Kensler TW, Smokers and urinary genotoxins: implications for selection of cohorts and modulation of endpoints in chemoprevention trials, J Cell Biochem Suppl, 1996, 25: 92-8.

[17] Ames B, Methods for detecting Carcinogens and mutagens with the salmonella/ mammalian micro some mutagenicity test, Mutation Res, 1975, 31: 347-364. 
[18] Bartczak AW, Sangaiah R, Ball LM, Warren SH1 and Gold A, Synthesis and bacterial mutagenicity of the cyclopenta oxides of the four cyclopenta-fused of isomers of benzanthracene, Mutagenesis, 2(2), 1987: 101-105.

[19] Varella SD, Rampazo RA, Varanda EA. Urinary mutagenicity in chemical laboratory workers exposed to solvents. J Occup Health, 2008, 50: 415-22.

[20] Siwińska E, Mielzyńska D, Kapka L. Association between urinary 1-hydroxypyrene and genotoxic effects in coke oven workers. Occup Environ Med, 2004, 61: e10.

[21] Chamberlain PL, Brynes SD. The regulatory status of xylazine for use in food-producing animals in the United States. J Vet Pharmacol Ther, 1998, 21: 322-9.

[22] Goodson-Gregg N and De Stasio EA Reinventing the Ames Test as a Quantitative Lab that Connects Classical and Molecular Genetics. Genetics , 2009,181: 21-30.

[23] Ming-Fang Wu, Fu-Chuo Peng, Yung-Liang Chen et al, Evaluation of Genotoxicity of Antrodia cinnamomea in the Ames Test and the In Vitro Chromosomal Aberration Test, in vivo,2011, 419-424.

[24] Meltem Boyacıŏ̆lu, Özlem Çakal Arslan, Hatice Parlak, Muhammet Ali Karaaslan, Mutagenicity of Nonylphenol and Octylphenol Using Salmonella Mutation Assay, E.U. Journal of Fisheries \& Aquatic Sciences, 2007, 299-302.

[25] Alva Biran, Rami Pedahzur, Sebastian Buchinger, Georg Reifferscheid , and Shimshon Belkin, Genetically Engineered Bacteria for Genotoxicity Assessment, Hdb Env Chem ,2009,161-186.

[26] Jadwiga Marczewska, Ewa Karwicka et al, Assessment of Cytotoxic and Genotoxic Activity of Alcohol Extract of Polyscias Filicifolia Shoot, Leaf, Cell Biomass of Suspension Culture and Saponin Fraction, Acta Poloniae Pharmaceutica,2011, 703710. 


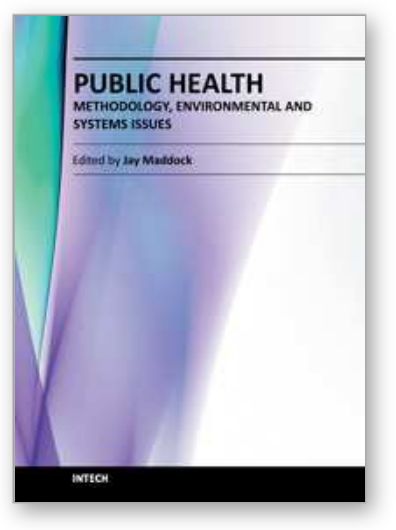

\author{
Public Health - Methodology, Environmental and Systems Issues \\ Edited by Prof. Jay Maddock
}

ISBN 978-953-51-0641-8

Hard cover, 432 pages

Publisher InTech

Published online 30, May, 2012

Published in print edition May, 2012

Public health can be thought of as a series of complex systems. Many things that individual living in high income countries take for granted like the control of infectious disease, clean, potable water, low infant mortality rates require a high functioning systems comprised of numerous actors, locations and interactions to work. Many people only notice public health when that system fails. This book explores several systems in public health including aspects of the food system, health care system and emerging issues including waste minimization in nanosilver. Several chapters address global health concerns including non-communicable disease prevention, poverty and health-longevity medicine. The book also presents several novel methodologies for better modeling and assessment of essential public health issues.

\title{
How to reference
}

In order to correctly reference this scholarly work, feel free to copy and paste the following:

Majid Rezaei Basiri, Mahmoud Ghazi-khansari, Hasan Rezazadeh, Mohammad Ali Eghbal, Iraj swadi-kermani, H. Hamzeiy, Hossein Babaei, Ali Reza Mohajjel Naebi and Alireza Partoazar (2012). Review of Ames Assay Studies of the Urine of Clinical Pathology and Forensic Laboratory Personnel and Other Occupations, such as Oncology Hospitals and Nursing Personnel, Public Health - Methodology, Environmental and Systems Issues, Prof. Jay Maddock (Ed.), ISBN: 978-953-51-0641-8, InTech, Available from:

http://www.intechopen.com/books/public-health-methodology-environmental-and-systems-issues/review-ofames-assay-studies-in-clinical-pathology-and-clinical-forensic-laboratories-and-other-

\section{INTECH}

open science | open minds

\section{InTech Europe}

University Campus STeP Ri

Slavka Krautzeka 83/A

51000 Rijeka, Croatia

Phone: +385 (51) 770447

Fax: +385 (51) 686166

www.intechopen.com

\section{InTech China}

Unit 405, Office Block, Hotel Equatorial Shanghai

No.65, Yan An Road (West), Shanghai, 200040, China

中国上海市延安西路65号上海国际贵都大饭店办公楼405单元

Phone: +86-21-62489820

Fax: $+86-21-62489821$ 
(C) 2012 The Author(s). Licensee IntechOpen. This is an open access article distributed under the terms of the Creative Commons Attribution 3.0 License, which permits unrestricted use, distribution, and reproduction in any medium, provided the original work is properly cited. 